\title{
Coagulants Pretreatment of Surface Water for Enhanced Performance of Ceramic Filters
}

\author{
E. Fosso-Kankeu*, C .M. van der Merwe, D. Moyakhe and J.R. Gumbo
}

\begin{abstract}
It has been reported that more than 1.8 billion people in the world did not have access to safe drinking water in 2015. Rural regions in developing countries are most susceptible to this issue. Water pollution can lead to waterborne diseases and therefore it is important that an effective water purification method is available for these households. Ceramic pot filters (CPFs) are currently the most effective way to treat polluted water in rural communities, due to the fact that it is a low-cost technology which can be produced locally. These filters do however get clogged easily causing a decrease in flow rate as well as a decrease in the filter's lifetime, causing people to neglect this water purification method. The effect of pre-treating the source water with a natural coagulant, Moringa oleifera, on the performance of the ceramic filter is assessed in this study. Moringa oleifera is one of the best natural coagulants, as it contains a soluble protein, which acts as a natural cationic polyelectrolyte, making coagulation in turbid water possible. The performance of Moringa oleifera is compared to that of conventional chemical coagulants namely; ferric chloride and aluminium sulphate. The use of coagulants as pre-treatment method is also compared to the use of a filter cloth. It is shown that the use of Moringa oleifera seeds as coagulant agent effectively removes the turbidity of contaminated water. Ferric chloride performs relatively better compared to Moringa oleifera in conditions where the contaminated water has a high turbidity. However, Moringa oleifera has shown to be more effective in conditions where the turbidity of the contaminated water is low. The filter cloth is not an effective method to pre-treat contaminated water, as the turbidity removal is insufficient. The performance of the ceramic filter is dependent on the porosity of the ceramic pot. The porosity of the filters is however not controlled due to the fact that the filters are manufactured by a local pottery in a village, which does not have access to the needed technology. Although the porosity of the filters varies, the turbidity is effectively reduced. Pre-treating the contaminated water does not have a significant effect on the ceramic
\end{abstract}

E. Fosso-Kankeu is with the Water Pollution Monitoring and Remediation Initiatives Research Group in the School of Chemical and Minerals Engineering of the North West University, Potchefstroom-South Africa. Email:

C. van der Merwe is with the Water Pollution Monitoring and Remediation Initiatives Research Group in the School of Chemical and Minerals Engineering of the North West University, Potchefstroom-South Africa.

Dumisane Moyakhe is with the Water Pollution Monitoring and Remediation Initiatives Research Group in the School of Chemical and Minerals Engineering of the North West University, Potchefstroom-South Africa.

Dumisane Moyakhe is with the Water Pollution Monitoring and Remediation Initiatives Research Group in the School of Chemical and Minerals Engineering of the North West University, Potchefstroom-South Africa.

J.R. Gumbo is with the Department of Hydrology \& water Resources, University of Venda, P/Bag x5050, Thohoyandou, 0950.

S. B. Author was with Rice University, Houston, TX 77005 USA. He is now with the Department of Physics, Colorado State University, Fort Collins, CO 80523 USA. filter's ability to reduce the turbidity, but it may however have an effect on the functionality of the filter over a long period of time.

The required amount of water intake per day for an adult male, adult female and a child who are living in average conditions is $2.9,2.2$, and $1.0 \mathrm{~L}$, respectively. An average flowrate of 0.317 $\mathrm{L} /$ hour was determined for the CPFs, therefore if the filter runs for 24 hours, only $7.61 \mathrm{~L}$ of water will be purified. The amount is not suitable for a household of more than 3 people, especially in high temperature regions.

Keywords-Moringa oleifera, Ceramic filters, Water purification, turbidity.

\section{INTRODUCTION}

Water is the main element required to sustain life and it is therefore of utmost importance that safe drinking water is available for everybody [1] which is defined as a human right [2].

More than 1.8 billion people in the world did not have access to safe drinking water in 2015, where approximately 150 million people relied on surface water for drinking water [3].

Rural areas in developing countries face the biggest shortage to safe drinking water. The people living in these rural areas depend on rainfall harvesting as well as surface water sources, such as rivers, ponds, lakes, springs and wells. These water sources are usually not treated before consumption, leading to waterborne diseases, which can cause mortalities, especially amongst young children [4-13].

Water pollution is mainly due to anthropogenic activities [14], which causes chemical, radiological or microbial contamination [1].

Household water treatment methods can be used to transform contaminated water into safe drink water. These methods include sedimentation and filtration [15-32].

During sedimentation, the suspended particles in the water settles out, leading to a reduction in turbidity. Coagulant agents can be used to accelerate the sedimentation process [15].

Moringa oleifera is classified as one of the best natural coagulants [33]-[35]. The Moringa oleifera seeds consists out of a soluble protein, which acts as a natural polyelectrolyte that has a positive charge [34]. Natural water, with a $\mathrm{pH}$ between 6 and 8 , are usually negatively charged [36]. Due to this nature of the seed, coagulation can take place in natural water that is turbid [34].

Suspended biological and/or chemical particles, causes the water to be turbid. The turbidity of water varies each season and can rapidly change during storage and transport. High turbidity levels can lead to the stimulation of bacterial growth. A turbidity 
of less than 1 NTU is ideally desired, but a turbidity of less than 5 is still acceptable [37].

The Moringa oleifera is easily cultivated and can grow in regions with a limited amount of rainfall and can therefore be grown locally in rural communities. Approximately $6000 \mathrm{~L}$ of contaminated water can be purified per year if a dosage of 50 $\mathrm{mg} / \mathrm{L}$ is used. This however depends on the amount of seed the tree can produce per year and the quality of the seeds [8]. During filtration, the particles present in the water are removed as it passes through the filter media. Ceramic pot filters are the most effective filter media that can be used in rural communities. It is low-cost, easy to handle, can be locally produced and it requires low maintenance [38], [39]. A disadvantage of ceramic filters is that they get clogged easily, leading to a decrease in flowrate. It therefore takes a longer time to purify the required amount of water, causing the users to become impatient and, the users then tend to reject the water purifying method. A temporary solution to the problem is to clean the ceramic pot through scrubbing it thoroughly, but an alternative solution is needed [38].

There is a required amount of water intake per person per day, and therefore it is necessary to either have a safe water source which will supply the amount needed or to have a water purification method which have the capacity to purify that amount per day. There are various aspects which determine the amount of water intake recommended for an individual per day, namely; physical activities, climate and the health of the individual. For healthy individuals who are moderately physically active and living in an average climate, it is recommended that the average volume of water intake required per day for an adult male, adult female and a child is $2.9,2.2$, and $1.0 \mathrm{~L}$, respectively. For conditions where manual labor is involved in high temperatures, it is required that for an adult male and an adult femalean increase of $4.5 \mathrm{~L}$ of water per day is considered [40].

The aim of this study is to assess the effect of pre-treating contaminated water with a natural coagulant, Moringa oleifera, on the performance of the ceramic filter. The ability of the coagulant as well as the ability of the ceramic filter to reduce the turbidity of the water will be assessed. The performance of Moringa oleifera compared to conventional coagulants will also be assessed.

\section{MATERIALS AND METHODS}

\section{A. Materials used}

For the coagulation procedure, powdered Moringa oleifera seeds were used a natural coagulant, while ferric chloride and aluminium sulphate were used as chemical coagulants. Another material that was used for the pre-treatment process was a muslin cloth which was used to filter the contaminated water before it was filtered through the ceramic filter. The performance of the filter cloth was assessed to determine how efficient it will be if it had to be used due to the unavailability of coagulant agents.

Ceramic filters made by artisans in the Limpopo Province of South Africa were used as the main filter media.

\section{B. Harvesting of Moringa oleifera seeds}

The pods which contain the Moringa oleifera seeds were obtained from a local farm in Ga-Masemola, a village located in Polokwane, GPS coordinates: $24^{\circ} 33^{\prime} 34.5^{\prime \prime S} 29^{\circ} 37^{\prime} 48.1^{\prime \prime E}$. After the pods had dried out, the seeds were removed from it and then shelled.

\section{Water sampling}

The contaminated water was sampled from a canal in Potchefstroom, GPS coordinates: $26^{\circ} 42^{\prime} 04.6^{\prime \prime S} 27^{\circ} 05^{\prime} 55.0^{\prime \prime} \mathrm{E}$. Plastic containers with a capacity of $25 \mathrm{~L}$ each were used. The sampled water was directly transported to the laboratory of the North West University of Potchefstroom, where all the tests were conducted. The parameters of the water were not adjusted and therefore it was important to conduct all the required tests for the sampled water in one day to ensure consistency.

The optimum coagulant dosage of the different coagulants was determined in the first stage of the tests. In order to be able to effectively compare the performance of the coagulants with one another, the same sampled water was used for all the different coagulants with their different dosages in one day.

For the second stage of the tests, the performance of the ceramic filters was assessed. This stage consisted of five runs, where the same sample of water had to be used for each individual run.

\section{Coagulation procedure}

The coagulation procedure consisted of two steps, where the stock solution of the different coagulants were first prepared, there after a jar test was conducted to allow coagulation to take place.

\section{1) Coagulant solution and dosing}

The shelled Moringa oleifera seeds were used as a natural coagulant for this study, while aluminium sulphate and ferric chloride were used as chemical coagulants. The performances of ferric chloride and aluminium sulphate were compared to that of Moringa oleifera.

For the stock solution of Moringa oleifera, a household coffee bean grinder was used to blend the shelled seeds into a fine powder. An optimum stock solution concentration of $2 \mathrm{~g}$ per $100 \mathrm{~mL}$ was obtained from literature [34]. The required amount of seed powder was weighed off and then wet to form a paste, then it was diluted to $100 \mathrm{~mL}$. The solution was stirred for 10 minutes, so that the particles could dissolve. It was then left to stand for 30 minutes, to ensure that all the undissolved particles settle out. The supernatant liquid was used for dosing. The desired stock solutions for ferric chloride and aluminium sulphate were $5 \mathrm{mg} \mathrm{Fe} e^{+} / \mathrm{mL}$ and $5 \mathrm{mg} \mathrm{Al}^{2+} / \mathrm{mL}$, respectively. It was calculated that $61.75 \mathrm{mg} / \mathrm{mL}$ of aluminium sulphate and $24.2 \mathrm{mg} / \mathrm{mL}$ of ferric chloride were required. Therefore 6.18 and $2.42 \mathrm{~g}$ of aluminium sulphate and ferric chloride, respectively, were diluted to $100 \mathrm{~mL}$.

The optimum dosage of each coagulant was first determined, the different dosages tested were $5,10,15$, and $25 \mathrm{~mL}$ of coagulant stock solution in $1 \mathrm{~L}$ of contaminated water. Therefore 4, 8, 12 and $24 \mathrm{~mL}$ of each coagulant were added to $800 \mathrm{~mL}$ of contaminated water. The jar test was conducted three times for each dosage to ensure accuracy. 
For the rest of the experiments, the optimum dosage for each coagulant was used. It was also concluded that ferric chloride performs better than aluminium sulphate and therefore only ferric chloride was used as the chemical coagulant.

\section{2) Jar test}

Standard jar test equipment was used to induce the interaction of the coagulants with the particles present in the contaminated water. The jar test equipment consisted of six paddles and therefore six $1 \mathrm{~L}$ tall beakers were used simultaneously.

The required dosage for each coagulant was added to 800 $\mathrm{mL}$ of contaminated water. Rapid mixing was first conducted for 2 minutes at $200 \mathrm{rpm}$, there after it was mixed slowly for 15 minutes at $50 \mathrm{rpm}$. After mixing, the mixture was left to stand for one hour, to ensure that all the formed flocs settle out. All the required parameters were then measured.

\section{E. Filtration procedure}

Ceramic filters were obtained from a local manufacturer, Mukondeni Pottery Village $\left(23^{\circ} 15^{\prime} 21.5^{\prime \prime} \mathrm{S} 30^{\circ} 06^{\prime} 14.3^{\prime \prime E}\right)$ in Ha-Mashamba. The filters consisted of a plastic container in which the ceramic pot was placed. The plastic container has a spigot and a lid.

The filtration procedure consisted of five runs, where fresh water has to be sampled for each run. Four ceramic filters were used, through which four different samples were filtered. These four different samples were the control (untreated water), the pre-treated water with the use of a filter cloth, the pre-treated water with the use of Moringa oleifera and the pre-treated water with the use of ferric chloride. The flow through the ceramic filter was measured and therefore it was important to use the specific filter for the specific sample each time.

For the first run, $12 \mathrm{~L}$ of each sample was filtered through its specific filter. The second to fifth run consisted of the filtration of $2 \mathrm{~L}$ of each samples through their specific filter.

The required parameters were measured before and after filtration, to determine the effectiveness of filtration.

\section{F. Analytical procedure}

The water parameter analyzed was turbidity while the Moringa oleifera was characterized using zeta potential and FT-IR.

After each sampling trip the control, which was the untreated water, was measured. This was to determine how effective the coagulation and filtration procedure was.

\section{1) Turbidity}

The sample's turbidity was measured with the $\mathrm{HACH}$ 2100Q turbidity meter. The water sample was poured into the turbidity glass container and shaken well to ensure that the particles were suspended in the water. Before the container was placed into the turbidity meter, it was wiped with a soft tissue to ensure that there were no finger prints on the container which will cause an inaccuracy in results. The measurements were taken five times to ensure accuracy of results.

\section{2) Zeta potential}

A NanoPlus Zeta/Nano particle analyser was used to determine the zeta potential of the Moringa oleifera stock solution.

\section{3) $F T-I R$}

A PerkinElmer spectrum apparatus was used to carry out Fourier-transform infrared spectroscopy (FT-IR) analysis of the Moringa oleifera seed. The FT-IR analysis specifies what functional groups are present in the material and therefore indicating the complex nature of the material.

\section{RESULTS AND DISCUSSION}

\section{A. Characterization of Moringa oleifera}

\section{1) Zeta potential}

The coagulation mechanism which is used for the Moringa oleifera seed is charge neutralization [36], [41]. The particles which are present in natural water, with a $\mathrm{pH}$ range of $6-8$, are generally negative. This charge is neutralized through the addition of positively charged coagulant agents, which cause the particles to form a cluster and settle out due to the van der Waals forces [36], [42].

For this study, zeta potential was used to measure the charge of the Moringa oleifera coagulant solution which was $7.02 \mathrm{mV}$, as seen in Fig. 1. The positive charge of the Moringa oleifera was therefore suitable for the removal of suspended particles in the water samples.

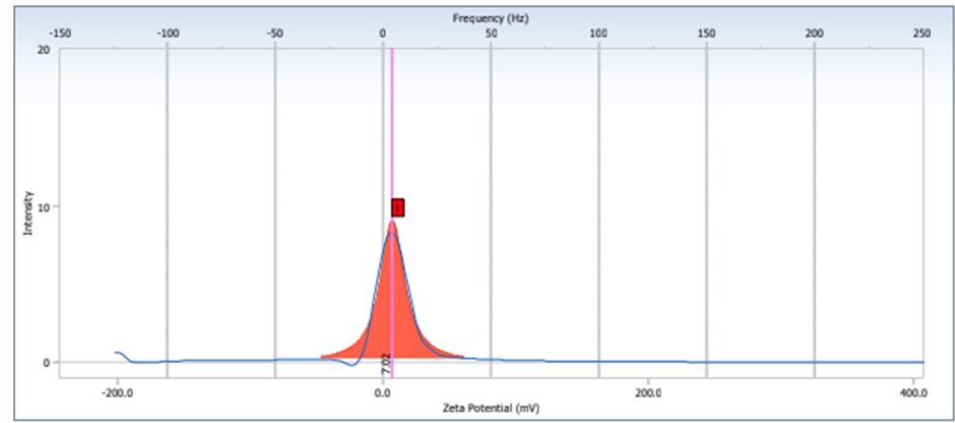

Fig. 1: Mobility distribution of Moringa oleifera seed

\section{2) $F T-I R$}

The complex nature of the Moringa oleifera seed is indicated through the FT-IR analysis that shows which functional groups are present in the material [43]. As seen in Fig. 2, the bandwidth with a peak present at $3284 \mathrm{~cm}^{-1}$ is due to the presence of strong $\mathrm{O}-\mathrm{H}$ bonds in proteins, carbohydrates and fatty acids. Medium strong C-H bonds of the alkane group is represented by the peaks at 2923 and $2853 \mathrm{~cm}^{-1}$, it is also shown by Fig. 2 that these bands have high intensities. The high intensities of the bands attest of the abundance of molecules carrying such groups in the seed. The peaks present at 1745 and $1649 \mathrm{~cm}^{-1}$ represents the presence of $\mathrm{C}=\mathrm{O}$ bonds.

\section{B. Optimum dosage}

The different dosage for the different coagulants were analyzed to determine the optimum dosage for each coagulant. The dosages tested were $5,10,15$, and $25 \mathrm{~mL}$ of coagulant stock 
solution in $1 \mathrm{~L}$ of contaminated water. For Moringa oleifera, an additional two dosages were added, 40 and $50 \mathrm{~mL}$, to broaden the dosage range. The control, which is the untreated contaminated water, had a turbidity of 184 NTU. As seen in Fig. 3 , the optimum dosage for Moringa oleifera was $15 \mathrm{~mL}$, while the tubidity was reduced to $1.78 \mathrm{NTU}$ and for ferric

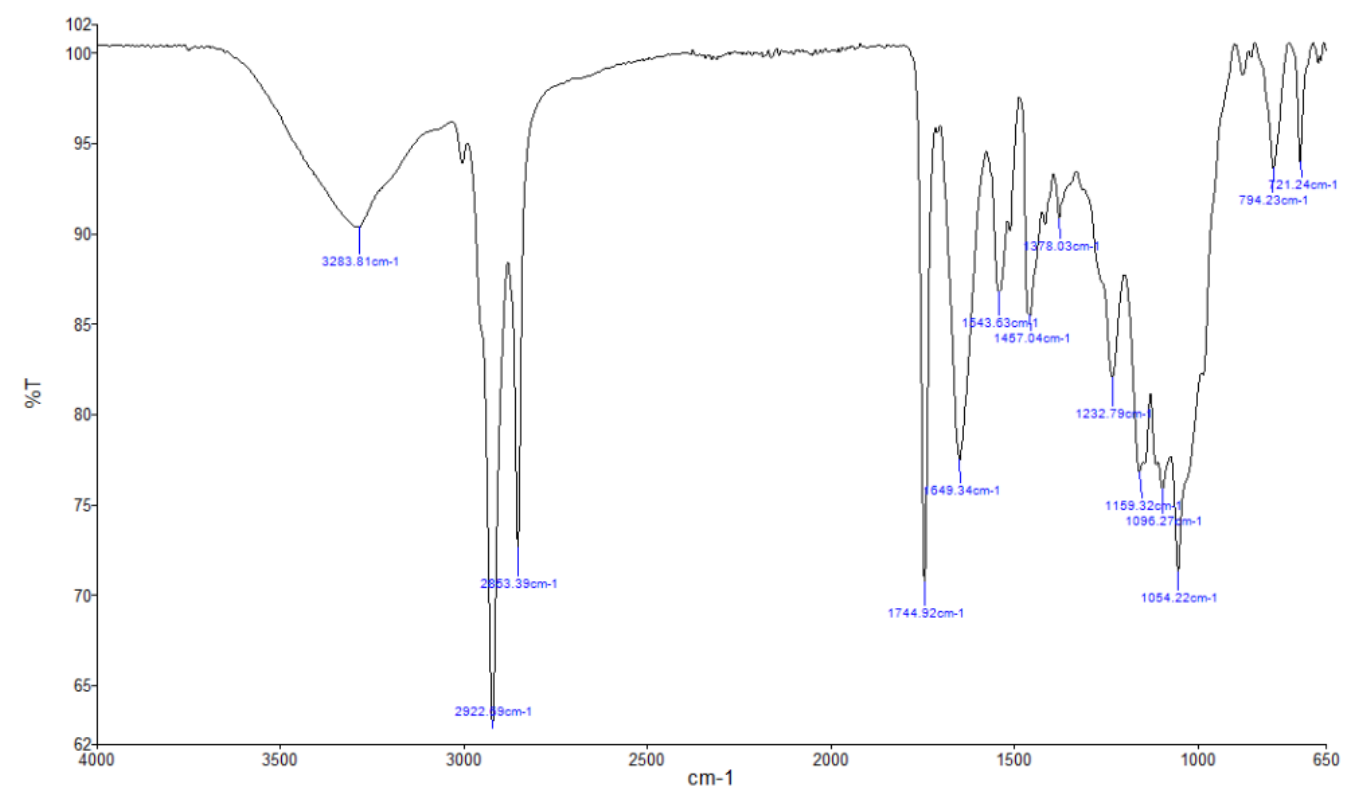

Fig. 2: FT-IT analysis of Moringa oleifera stock solution

chloride the optimum dosage was $5 \mathrm{~mL}$, where the turbidity was reduced to $1.90 \mathrm{NTU}$. Aluminium sulphate, with an optimum dosage of $5 \mathrm{~mL}$, did not perform as well in comparison to ferric chloride, as the turbidity was only reduced to 2.33 NTU. Ferric chloride was the only chemical coagulant which was used for the remaining experiments.

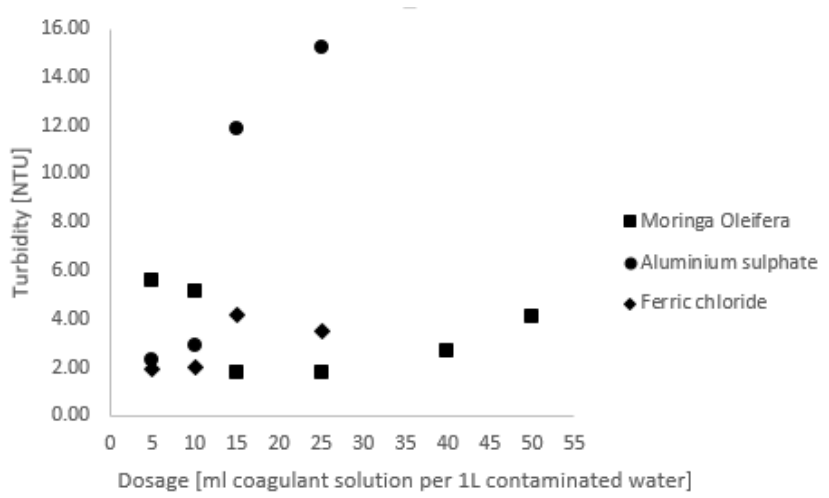

Fig. 3: Optimum dosage of coagulants

\section{Turbidity}

The turbidity of the control, which is the untreated water, influences the turbidity removal of the Moringa oleifera coagulant [36]. It can be seen in Table I, that the turbidity is reduced from $501 \mathrm{NTU}$ to $5.41 \mathrm{NTU}$ with the use of Moringa oleifera in the first run. For a lower turbidity in control, the performance of Moringa oleifera is higher as the turbidity is reduced from 86.6 NTU to $2.23 \mathrm{NTU}$ in the second run.

The ferric chloride is more efficient compared to Moringa oleifera for an initial higher turbidity in control, but less effective for a lower turbidity in control.

The filter cloth does not effectively reduce the turbidity of the water and is therefore not seen as an alternative to treating contaminated water, nor to pre-treating contaminated water before filtering it through a ceramic filter.

The performance of the ceramic filter is dependent on the porosity of the ceramic pot. The porosity of the filters could however not be controlled due to the fact that the filters were manufactured by a local pottery in a village, which does not have access to the needed technology. Although the porosity of the filters varies, the turbidity is effectively reduced, as seen in Table I. Pre-treating the contaminated water does not have a significant effect on the ceramic filter's ability to reduce the turbidity, but it may however have an effect on the functionality of the filter over a long period of time. 
TABLE I: MEASURED TURBIDITY (NTU)

\begin{tabular}{llllll}
\hline \hline & & Control & $\begin{array}{l}\text { Moringa } \\
\text { oleifera }\end{array}$ & $\begin{array}{l}\text { Ferric } \\
\text { chloride }\end{array}$ & Filter cloth \\
\hline \hline $\begin{array}{l}\text { Run 1: } \\
\text { Before } \\
\text { filtration }\end{array}$ & ceramic & 501 & 5.41 & 2.23 & 367 \\
$\begin{array}{l}\text { After } \\
\text { filtration }\end{array}$ & ceramic & 1.68 & 0.98 & 0.69 & 1.03 \\
$\begin{array}{l}\text { Run 2: } \\
\text { Before } \\
\text { filtration }\end{array}$ & ceramic & 86.6 & 2.23 & 3.97 & 72.9 \\
$\begin{array}{l}\text { After } \\
\text { filtration }\end{array}$ & ceramic & 1.15 & 1.12 & 0.806 & 1.03 \\
\hline \hline
\end{tabular}

\section{E. Flow through $C P F s$}

An average flowrate of $0.317 \mathrm{~L} /$ hour was determined for the CPFs, therefore if the filter runs for 24 hours, only $7.61 \mathrm{~L}$ of water will be purified. In South Africa, an average amount of 3 to 4 people lives in one household [44]. The capacity of the $\mathrm{CPFs}$ in not adequate to produce the required amount of water needed for households of more than three people in moderate conditions. It also does not produce enough water for a household of 3 people in rural areas with high temperatures.

\section{CONCLUSION}

It is concluded that the pre-treatment of contaminated water with the use of Moringa oleifera as coagulant agent is effective, as it effectively reduces the turbidity of the contaminated water. Compared to the conventional coagulant, ferric chloride, Moringa oleifera performs better for contaminated water with a lower turbidity.

It is further concluded that although the porosity of the CPFs differ from one another, the filters still effectively reduces the turbidity. The amount of water purified in one day through the use of the CPFs are however not sufficient for a household of 3 or more people, especially in high temperature regions. A more effective water treatment method is required, which can not only sufficiently purify the water, but can also purify large amount which will sustain a household.

\section{ACKNOWLEDGMENT}

The authors acknowledge support from the North-West University. Laboratory assistance from $\mathrm{Mr} \mathrm{N}$ Lemmer at the North-West University and Mr J. Nyembwe and Ms N Baloyi at the University of Johannesburg.

\section{REFERENCES}

[1] World Health Organization, Guidelines for drinking-water quality, 4th ed. 2011.

[2] J. Santiago Ortiz-Correa, M. Resende Filho, and A. Dinar, "Impact of access to water and sanitation services on educational attainment," Water Resour. Econ., vol. 14, pp. 31-43, 2016. https://doi.org/10.1016/j.wre.2015.11.002

[3] World Health Organization (WHO) and United Nations Children's Fund (UNICEF), Progress on drinking water, sanitation and hygiene. 2017.

[4] J. N. Edokpayi et al., "Challenges to sustainable safe drinking water: A case study ofwater quality and use across seasons in rural communities in Limpopo Province, South Africa," Water (Switzerland), vol. 10, no. 2, pp. 159-167, 2018. https://doi.org/10.3390/w10020159
[5] E. Fosso-Kankeu, P. Jagals, H. Du Preez, Exposure of rural households to toxic cyanobacteria in container-stored water. Water SA, Vol. 34, no. 5, pp. 631-636, 2008.

https://doi.org/10.4314/wsa.v34i5.180660

[6] E. Fosso-Kankeu, A. Mulaba-Bafubiandi, B.B. Mamba, T.G. Barnard, Mitigation of $\mathrm{Ca}, \mathrm{Fe}$, and $\mathrm{Mg}$ loads in surface waters around mining areas using indigenous microorganism strains. Journal of Physics and Chemistry of the Earth, Vol. 34, pp. 825-829, 2009. https://doi.org/10.1016/j.pce.2009.07.005

[7] E. Fosso-Kankeu, H. Du Preez, P. Jagals, The health implication of relationships between bacterial endotoxin, cyanobacteria, coliforms and water stored in domestic containers of rural households in South Africa. Journal of Water and Health, Vol. 8, no. 4, pp. 601-610, 2010. https://doi.org/10.2166/wh.2010.094

[8] M.S. Mamba, A.K. Mishra, B.B. Mamba, P.B. Njobeh, M.F. Dutton, E. Fosso-Kankeu, Spectral, thermal and in-vitro antimicrobial studies of cyclohexylamine- $N$ dithiocarbamate transition metal complexes. Spectrochemica Acta A:Molecular and Biomolecular Spectroscopy, Vol. 77, no. 3, pp. 579-587, 2010.

https://doi.org/10.1016/j.saa.2010.06.002

[9] E. Fosso-Kankeu, A. Mulaba-Bafubiandi, B.B. Mamba, L. Marjanovic, T.G. Barnard, A comprehensive study of physical and physiological parameters that affect biosorption of metal pollutants from aqueous solutions. Journal of Physics and Chemistry of the Earth, Vol. 35, pp. 672-678, 2010.

https://doi.org/10.1016/j.pce.2010.07.008

[10] A. Manyatshe, E. Fosso-Kankeu, D. van der Berg, N. Lemmer, F. Waanders, H. Tutu, Dispersion of inorganic contaminants in surface water in the vicinity of Potchefstroom. Physics and Chemistry of the Earth. Vol. 100, pp. 86-93, 2017. https://doi.org/10.1016/j.pce.2017.04.008

[11] C. de Klerk, E. Fosso-Kankeu, F.B. Waanders, Evaluation of the antibacterial activity of metal impregnated multi-walled carbon nanotubes: impact of domestic wastewater as supporting medium. Desalination and Water Treatment.Vol. 99, pp. 272-281, 2017. https://doi.org/10.5004/dwt.2017.21735

[12] A. Manyatshe, E. Fosso-Kankeu, D. van der Berg, N. Lemmer, F. Waanders, H. Tutu, Metal speciation in the rivers around Potchefstroom based on seasonality. Water Environment Research. Vol. 90, no. 1, pp. 84-95, 2018. https://doi.org/10.2175/106143017X15054988926587

[13] C. de Klerk, E. Fosso-Kankeu, L. Du Plessis and S. Marx, Assessment of the viability of Saccharomyces cerevisiae in response to synergetic inhibition during bioethanol production. Current Sciences. 2018. https://doi.org/10.18520/cs/v115/i6/1124-1132

[14] P. Chatanga, V. Ntuli, E. Mugomeri, T. Keketsi, and N. V. T. Chikowore, "Situational analysis of physico-chemical, biochemical and microbiological quality of water along Mohokare River, Lesotho," Egypt. J. Aquat. Res., vol. 45, no. 1, pp. 45-51, 2019. https://doi.org/10.1016/j.ejar.2018.12.002

[15] World Health Organization (WHO), "Household Household Water Water Treatment Treatment and and Safe Safe Storage," 2013.

[16] E. Fosso-Kankeu; O. Ntwampe, F. Waanders, and A. Webster, The Performance of Polyaluminium Chloride and Bentonite clay Coagulant in the Removal of Cationic and Anionic Dyes. $7^{\text {th }}$ International Conference on Latest Trends in Engineering and Technology (ICLTET' 2015), November 26-27, 2015 Irene, Pretoria (South Africa). Editors: E. Muzenda and T Yingthawornsuk. ISBN: 978-93-84422-58-5. 2015.

[17] E. Fosso-Kankeu, F. Waanders, R. Swiegers, I.O. Ntwampe, D. Rogers, G. Gericke, Impact of the physico-chemical properties of water on the flocculation performance of lime, clay and other polymers. International Conference on Advances in Science, Engineering, Technology and Natural Resources (ICASETNR-16) Nov. 24-25, 2016, Parys - South Africa. ISBN: 978-93-84468-79-8. 2016.

[18] E. Fosso-Kankeu, F.B. Waanders, G. Gericke, N. Lemmer, L.M. Dreyer and J. van der Linde, Investigation of the potential of monomeric and polymeric coagulants in the treatment of raw water used at a coal-fired power station. $9^{\text {th }}$ Int'l Conference on Advances in Science, Engineering, Technology \& Waste Management (ASETWM-17). 27-28 November 2017, Parys, South Africa. Editors: F. Waanders, E. Fosso-Kankeu, B. Topcuoglu, M. Plaisent, Y. Thaweesak. ISBN: 978-81-934174-6-1. Pp. 44-48. 2017. 
[19] D.M. Moyakhe, Q.P. Campbell, E. Fosso-Kankeu, The effect of flocculant type on settling properties of fine coal tailings. $9^{\text {th }}$ Int'1 Conference on Advances in Science, Engineering, Technology \& Waste Management (ASETWM-17). 27-28 November 2017, Parys, South Africa. Editors: F. Waanders, E. Fosso-Kankeu, B. Topcuoglu, M. Plaisent, Y. Thaweesak. ISBN: 978-81-934174-6-1. Pp. 165-168. 2017.

[20] J.C. van der Linde, E. Fosso-Kankeu, G. Gericke, N. Lemmer, and F. Waanders, Removal of Total Hardness and Alkalinity from RO - reject water. $9^{\text {th }}$ Int'l Conference on Advances in Science, Engineering, Technology \& Waste Management (ASETWM-17). 27-28 November 2017, Parys, South Africa. Editors: F. Waanders, E. Fosso-Kankeu, B. Topcuoglu, M. Plaisent, Y. Thaweesak. ISBN: 978-81-934174-6-1. Pp. 147-151. 2017.

[21] Elvis Fosso-Kankeu, Christiaan Steyn van der Vyver, Corli de Klerk, Dumisane Moyakhe and Frans Waanders. 2018. Brewery effluent sludge characterization and dewatering to increase potential water recycling capabilities. Editors: Elvis Fosso-Kankeu, Frans Waansders, Michel Plaisent. 10th Int'l Conference on Advances in Science, Engineering, Technology \& Healthcare (ASETH-18) Nov. 19-20, 2018 Cape Town (South Africa). ISBN: 978-81-938365-2-1. Vol I. Pp 106-114.

[22] JC van der Linde, E Fosso-Kankeu, G Gericke, F Waanders and T. Tamane. 2018. Effect of Temperature on the Performance of Rheofloc: Conductivity Removal from RO-reject. Editors: Elvis Fosso-Kankeu, Frans Waansders, Michel Plaisent. 10th Int'l Conference on Advances in Science, Engineering, Technology \& Healthcare (ASETH-18) Nov. 19-20, 2018 Cape Town (South Africa). ISBN: 978-81-938365-2-1. Vol II. Pp 139-143.

[23] E. Fosso-Kankeu, L. Van Schalkwyk, J. Van Der Linde, G. Gericke and F.B. Waanders. 2018. Pretreatment of Coal Power Plant RO Retentate using AR Floc 100. Editors: Elvis Fosso-Kankeu, Frans Waansders, Michel Plaisent. 10th Int'l Conference on Advances in Science, Engineering, Technology \& Healthcare (ASETH-18) Nov. 19-20, 2018 Cape Town (South Africa). ISBN: 978-81-938365-2-1. Vol II. Pp 149-154.

[24] I.O. Ntwampe, F.B. Waanders, E. Fosso-Kankeu and J.R. Bunt, Turbidity removal efficiency of clay and a synthetic af-PFCl Polymer of Magnesium Hydroxide in AMD Treatment. International Scientific Research Journal. Vol. 4, pp. 38-55, 2015. https://doi.org/10.18483/IRJSci.74

[25] I.O. Ntwampe, F.B. Waanders, E. Fosso-Kankeu, J.R. Bunt, Reaction dynamics of iron and aluminium salts dosage in AMD using shaking as an alternative technique in the destabilization-hydrolysis process. International Scientific Research Journal. Vol. 1, no. 8, pp. 5-23, 2015. https://doi.org/10.18483/IRJSci.73

[26] E. Fosso-Kankeu, H. Mittal, F. Waanders, I.O. Ntwampe, S.S. Ray, Preparation and characterization of gum karaya hydrogel nanocomposite flocculant for metal ions removal from mine effluents. International Journal of Environmental Science and Technology. Vol. 13, pp. 711-724, 2016. https://doi.org/10.1007/s13762-015-0915-x

[27] E. Fosso-Kankeu, A. Webster, I.O. Ntwampe, F.B. Waanders, Coagulation/flocculation potential of polyaluminium chloride and bentonite clay tested in the removal of methyl red and crystal violet. Arabian Journal for Science and Engineering. DOI 10.1007/s13369-016-2244-x. 2016.

[28] E. Fosso-Kankeu, H. Mittal, S. Marx and S.S. Ray, Hydrogel-based bioflocculants for the removal of organic pollutants from biodiesel wastewater. Journal of Polymer and Environment. DOI 10.1007/s10924-016-0870-8. 2016.

[29] Elvis Fosso-Kankeu. 2019. Nano and Bio-based Technologies for wastewater treatment: Prediction and Control Tools for the dispersion of Pollutants in the Environment. Wiley Scrivener. ISBN: 978-1-119-57709-6. Pp 301-336.

[30] Elvis Fosso-Kankeu. 2019. New Horizons in Wastewaters Management: Emerging Monitoring and Remediation Strategies. Nova Science Publishers. ISBN: 978-1-53615-659-1.

[31] Johannes Cornelius van der Linde, Elvis Fosso-Kankeu, Gerhard Gericke, Frans Waanders, Louise Dreyer, Nico Lemmer. 2019. Flocculant types and operating conditions influencing particles settling rates in feed water used at a coal power plant. Desalination and Water Treatment. 150: 293-300.

https://doi.org/10.5004/dwt.2019.23735
[32] E. Fosso-Kankeu, F. Waanders, A.F. Mulaba-Bafubiandi, A.K. Mishra. 2016. Flocculation performances of polymers and nanomaterials for the treatment of industrial wastewaters. In A.K. Mishra (ed). 2016. Smart Materials for Waste Water Applications. Wiley Scrivener. ISBN: 9781119041184. Pp 213 - 235. https://doi.org/10.1002/9781119041214.ch8

[33] G. S. Madrona, G. B. Serpelloni, A. M. Salcedo Vieira, L. Nishi, K. C. Cardoso, and R. Bergamasco, "Study of the effect of Saline solution on the extraction of the Moringa oleifera seed's active component for water treatment," Water. Air. Soil Pollut., vol. 211, no. 2010, pp. 409-415, 2010. https://doi.org/10.1007/s11270-009-0309-0

[34] M. Pritchard, T. Craven, T. Mkandawire, A. S. Edmondson, and J. G. O'Neill, "A comparison between Moringa oleifera and chemical coagulants in the purification of drinking water - An alternative sustainable solution for developing countries," Phys. Chem. Earth, vol. 35 , no. 2010 , pp. $798-805,2010$ https://doi.org/10.1016/j.pce.2010.07.014

[35] J. Dotto, M. R. Fagundes-Klen, M. T. Veit, S. M. Palácio, and R. Bergamasco, "Performance of different coagulants in the coagulation/flocculation process of textile wastewater," J. Clean. Prod., vol. 208, no. 2019, pp. 656-665, 2019. https://doi.org/10.1016/j.jclepro.2018.10.112

[36] Y. Jung, Y. Jung, M. Kwon, H. Kye, Y. W. Abrha, and J. W. Kang, "Evaluation of Moringa oleifera seed extract by extraction time: Effect on coagulation efficiency and extract characteristic," J. Water Health, vol. 16 , no. 6, pp. 904-913, 2018. https://doi.org/10.2166/wh.2018.078

[37] World Health Organization (WHO), "Water quality and health - Review of turbidity: Information for regulators and water suppliers," 2017.

[38] C. Salvinelli, "Lifetime and effectiveness evaluation of ceramic pot filters," 2016.

[39] D. van Halem, H. van der Laan, S. G. J. Heijman, J. C. van Dijk, and G. L. Amy, "Assessing the sustainability of the silver-impregnated ceramic pot filter for low-cost household drinking water treatment," Phys. Chem. Earth, vol. 34, no. 1-2, pp. 36-42, 2009. https://doi.org/10.1016/j.pce.2008.01.005

[40] G. Howard and J. Bartram, Domestic water quality, service level and health. Geneva: World Health Organization, 2003.

[41] A. Ndabigengesere, K. S. Narasiah, and B. G. Talbot, "Quality of water treated by coagulation using Moringa oleifera seeds," Water Reasearch, vol. 32, no. 3, pp. 781-791, 1998. https://doi.org/10.1016/S0043-1354(97)00295-9

[42] W. J. Snodgrass, M. M. Clark, and C. R. O'Melia, "Particle formation and growth in dilute aluminum(III) solutions: Characterization of particle size distributions at pH 5.5," Water Res., vol. 18, no. 4, pp. 479-488, 1984. https://doi.org/10.1016/0043-1354(84)90157-X

[43] C. S. T. Araujo et al., Bioremediation of Waters Contaminated with Heavy Metals Using Moringa oleifera Seeds as Biosorbent, no. May 2015. Rijeka: InTech, 2013. https://doi.org/10.5772/56157

[44] United Nations (Department of Economic and Social Affairs), Household size and composition around the world 2017 - Data booklet. 2017.

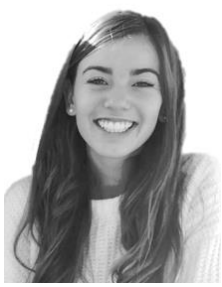

C.M. van der Merwe was born in Klerksdorp, North West province on the $16^{\text {th }}$ of July, 1997. She is currently in her final year ofstudying for her degree in Chemical Engineering at the North West University of Potchefstroom.

She has done summer work at ESKOM, where she was placed at Lethabo power station. A thermodynamic analysis of the plant was done, during her time there. 